\title{
Magnesium-catalyzed hydroboration of terminal and internal alkynes
}

\author{
Marc Magre, Bholanath Maity, Alban Falconnet, Luigi Cavallo* and Magnus Rueping*
}

\begin{abstract}
A magnesium-catalyzed hydroboration of alkynes providing good yields and selectivities for a wide range of terminal and symmetrical and unsymmetrical internal alkynes has been developed. The compatibility with many functional groups makes this magnesium catalyzed procedure attractive for late stage functionalization. Experimental mechanistic investigations and DFT calculations reveal insights into the reaction mechanism of the magnesium catalyzed protocol.
\end{abstract}

The synthesis of organoboron compounds is an important task due to the facile conversion of carbon-boron bonds into various carbon-carbon and carbon-heteroatom bonds. ${ }^{1}$ In particular, transition-metal catalysis has emerged as an important synthetic strategy for the synthesis of vinylboranes through the hydroborylation of alkynes. Although precious transition-metals have played an important role in achieving the borylation of unsaturated bonds, ${ }^{2}$ the use of more earth-abundant metals has attracted considerable attention in recent years. ${ }^{3-6}$

In this context group 2 alkaline-earth metals such as magnesium and calcium are among the most abundant metals in the earth's crust. However, their application in homogeneous catalysis has been scarce. Regarding the functionalization of alkenes and alkynes, the application of group 2 metals has been mainly focused on the inter- and intramolecular hydroaminations of activated alkenes, using $\mathrm{Ca}^{\mathrm{II}}, \mathrm{Sr}^{\mathrm{Il}}$ and $\mathrm{Ba}^{\mathrm{Il}}$ as catalysts. ${ }^{7}$

Regarding hydroboration of unsaturated bonds, in the last decade, diorganomagnesium catalysts have emerged as an alternative for the hydroboration of polarized unsaturated bonds in aldehydes, ketones, esters, imines, nitriles, sulfones and pyridines, among others. ${ }^{7-8}$

Magnesium-hydride species remained unknown until 2010, when Jones and Stasch reported the first structurally characterized Mg-hydride complexes. ${ }^{9}$ Since then, many efforts have been made to fully understand the alkaline-earth metal hydride chemistry and their application to catalytic transformations in which a metal-hydride center is involved. ${ }^{10}$

Although the magnesium hydroboration of polarized unsaturated bonds has been widely studied, to the best of our knowledge, there is no example in the literature describing the $\mathrm{Mg}^{\mathrm{II}}$ -

[*] Dr. M. Magre, MSc. A. Falconnet, Prof. Dr. M. Rueping Institute of Organic Chemistry RWTH Aachen

Landoltweg 1, 52074 Aachen (Germany)

E-mail: magnus.rueping@rwth-aachen.de

Dr. B. Maity, Prof. Dr. L. Cavallo, Prof. Dr. M. Rueping

KAUST Catalysis Center (KCC), Ling Abdullah University of Science and Technology (KAUST)

Thuwal, 23955-6900 (Saudi Arabia)

E-mail: luigi.cavallo@kaust.edu.sa

Supporting information for this article is given via a link at the end of the document. catalyzed hydroboration of non-polarized unsaturated carboncarbon bonds. ${ }^{11}$ Herein, we report an efficient method for the synthesis of vinyl boranes via a $\mathrm{MgBu}_{2}$-catalyzed hydroboration of terminal and internal alkynes (Scheme 1).

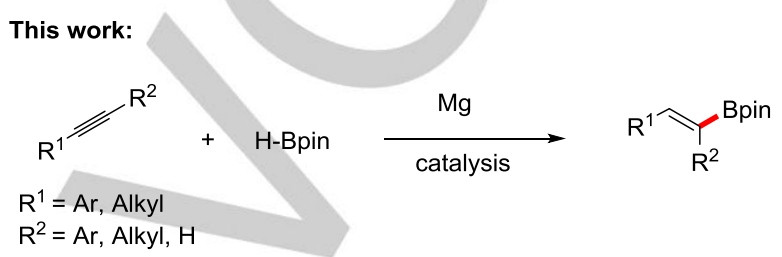

Scheme 1. Magnesium-catalyzed hydroboration of terminal and internal alkynes.

We began our investigations of the magnesium catalyzed hydroboration of phenyl acetylene $\mathbf{1 a}$ by evaluating the catalytic activity of readily available $\mathbf{M g B u}_{2}$ in the presence of $\mathbf{L} 1$ and $\mathbf{L 2}$ diketimine ligands ${ }^{12}$ (Table 1)

Performing the reaction with ligand $\mathbf{L 1}$ in toluene at $80{ }^{\circ} \mathrm{C}$ afforded the corresponding $\beta-(E)$-vinyl borane $2 \mathbf{a}$ in moderate yield and excellent selectivity (Table 1, entry 2 ). When ligand L2 was tested, the product $\beta-(E)-2 a$ was obtained in higher yield (Table 1, entry 2 vs entry 7). To our surprise, use of $\mathrm{MgBu}_{2}$ as the catalyst proved to be more active than the corresponding L1$\mathbf{M g}$ and L2-Mg complexes (Table 1, entry 8). ${ }^{13-14}$ Finally, by decreasing the catalyst loading (7 mol\%) and increasing the concentration, the desired $\beta-(E)$-vinyl borane $\mathbf{2 a}$ was obtained in $83 \%$ yield (Table 1 , entry 10$)$.

With the optimized reaction conditions in hand we explored the scope and limitations of this alkaline-earth metal catalyzed hydroboration of terminal alkynes (Table 2). We started investigating different phenyl acetylene derivatives and were pleased to see that substituents with different electronic properties on the aromatic ring (1a-1g) did not influence the catalytic activity. It is worth mentioning the good yield attained for the hydroboration of phenyl acetylene derivative $\mathbf{1 g}$, containing an amino group. We assume that $\mathrm{MgBu}_{2}$ shows milder reactivity compared to the corresponding aluminium catalyst, which failed in the hydroboration of 19-type alkynes. ${ }^{5}$ We also observed that the presence of different substituents in the ortho-position of the aromatic ring $(\mathbf{1} \mathbf{h}-\mathbf{1 m})$ did not decrease the good yields.

Next, we studied the scope of the transformation by applying terminal alkynes bearing alkyl substituents (1n-1r), which behaved similarly to the corresponding phenyl acetylene derivatives. When increasing the steric demand on the alkyl substituent (1n-1q), the yields were maintained. 
Table 1. Optimization of Mg-catalyzed hydroboration of phenyl acetylene..$^{\text {[a] }}$

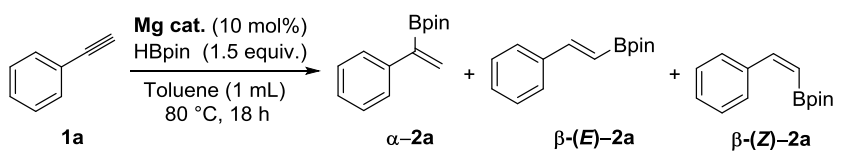

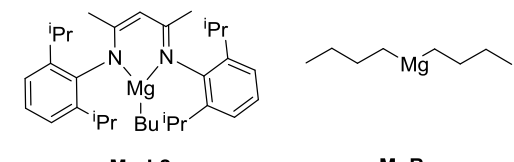

\begin{tabular}{|c|c|c|c|c|}
\hline \multicolumn{2}{|c|}{ Mg-L1 } & \multirow[b]{2}{*}{ Solvent } & \multicolumn{2}{|c|}{$\mathrm{MgBu}_{2}$} \\
\hline Entry & $\begin{array}{l}\text { Catalyst } \\
\text { (mol\%) }\end{array}$ & & $\begin{array}{l}\text { Selectivity } \\
\beta-(E)-2 \mathbf{a}(\%)^{[b]}\end{array}$ & $\begin{array}{l}\text { Yield } \\
(\%)^{[c]}\end{array}$ \\
\hline $1^{[\mathrm{d}]}$ & Mg-L1 (10) & Toluene & $>99$ & 10 \\
\hline 2 & Mg-L1 (10) & Toluene & $>99$ & 55 \\
\hline 3 & Mg-L1 (10) & THF & n.d. & $<5$ \\
\hline 4 & Mg-L1 (10) & Hexane & $>99$ & 37 \\
\hline 5 & Mg-L1 (10) & Cyclohexane & $>99$ & 52 \\
\hline 6 & Mg-L1 (10) & MTBE & $>99$ & 47 \\
\hline 7 & Mg-L2 (10) & Toluene & $>99$ & 74 \\
\hline 8 & $\mathrm{MgBu}_{2}(10)$ & Toluene & $>99$ & 80 \\
\hline $9^{[e]}$ & $\mathrm{MgBu}_{2}(10)$ & Toluene & $>99$ & 88 \\
\hline $10^{[\mathrm{e}]}$ & $\mathrm{MgBu}_{2}(7)$ & Toluene & $>99$ & $86(83)$ \\
\hline $11^{[\mathrm{e}]}$ & $\mathrm{MgBu}_{2}(5)$ & Toluene & $>99$ & 50 \\
\hline 12 & - & Toluene & n.d. & $<5$ \\
\hline
\end{tabular}

[a] $\mathrm{MgBu}_{2}$ (1M in heptane) (10 mol\%), L1 or L2 (12 mol\%), phenyl acetylene (1a, $0.5 \mathrm{mmol}), 1.5$ equiv. of HBpin, solvent $(1 \mathrm{~mL}, 0.5 \mathrm{M})$, at $80^{\circ} \mathrm{C}$ for $18 \mathrm{~h}$. [b] Determined by GC and ${ }^{1} \mathrm{H}$ NMR spectroscopy. [c] Determined by GC using $n$ dodecane as internal standard. Yield after isolation in parentheses. [d] Reaction at $60^{\circ} \mathrm{C}$. [e] $1 \mathrm{M}$ reaction concentration.

We also observed that even hydroboration of terminal dialkyne 1s took place smoothly, providing $2 s$ in good yield. Finally, we tested the efficiency of the Mg-catalyzed hydroboration of terminal alkynes $\mathbf{1 t} \mathbf{- 1} \mathbf{v}$ containing functional groups. Importantly, the ${ }^{\mathrm{i}} \mathrm{Pr}_{3} \mathrm{Si}$-group as well as hydroxyl groups were well tolerated, affording the corresponding vinyl borane $2 \mathbf{t}-\mathbf{v}$ in good yields. Thus, the magnesium-catalyzed protocol is rather general and provides good yields and selectivities in the the hydroboration of a wide range of terminal alkynes, bearing different aromatic as well as alkyl substituents. In addition, different functional groups are tolerated under the mild reaction conditions which could not be afforded with other catalysts reported in the literature..$^{4-5}$

In order to further expand the substrate scope, we decided to examine the Mg-catalyzed hydroboration of internal alkynes (Table 3). We started our investigation by testing symmetric alkynes as model substrates. In this case, slightly higher catalyst loading (10 mol\%) and in some cases longer reaction times were required to achieve good yields for diaryl and dialkyl alkynes 3a-3c.

Table 2. $\mathrm{MgBu}_{2}$-catalyzed hydroboration of terminal alkynes. ${ }^{[\mathrm{a}]}$

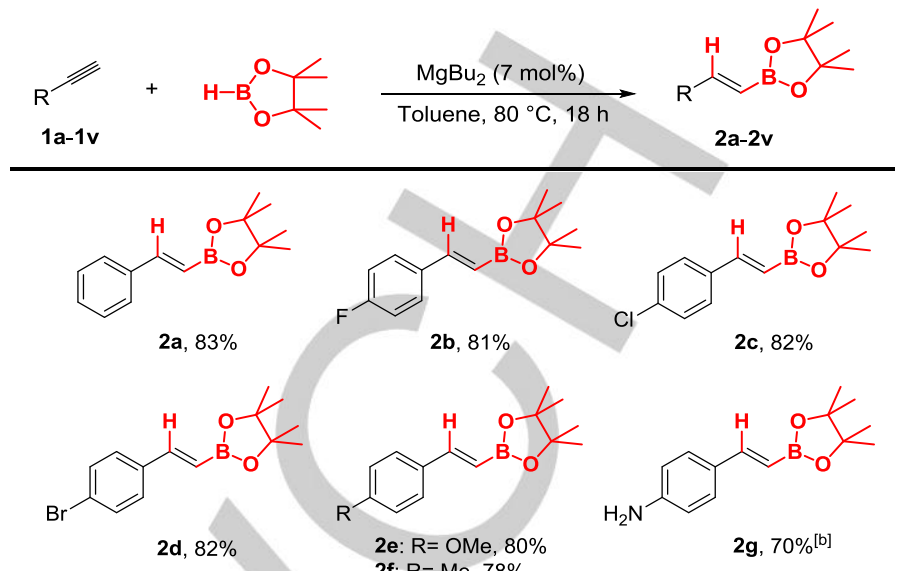

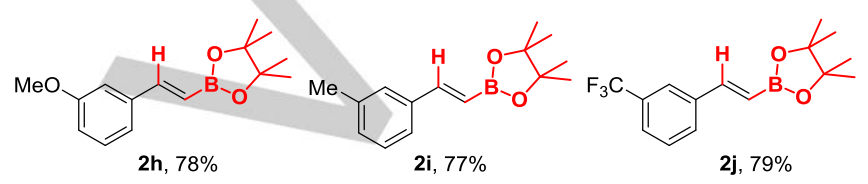

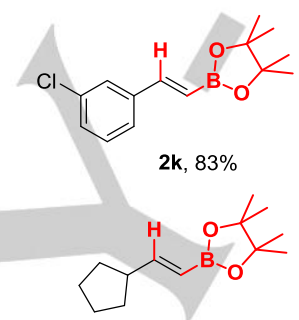

2n, $80 \%$<smiles>Cc1ccccc1/C=C/B1OC(C)(C)C(C)(C)O1</smiles>

2I, $80 \%$<smiles>CC1(C)OB(/C=C/C2CCCCC2)OC1(C)C</smiles>

$20,78 \%$

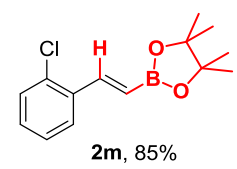<smiles>CC1(C)OB(/C=C/C2=CCCCC2)OC1(C)C</smiles>

$$
\text { (Pr) } \mathrm{Si}_{2 \mathrm{C}}
$$

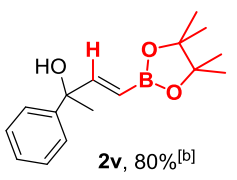

[a] Reaction conditions: $\mathbf{1 a}-1 \mathbf{v}(1 \mathrm{mmol}), 1.5$ equiv. $\mathrm{HBpin}, \mathrm{MgBu}_{2}(7 \mathrm{~mol} \%)$, toluene $(1 \mathrm{~mL}), 80^{\circ} \mathrm{C}$ for $18 \mathrm{~h}$. [b] 2.5 equiv. of HBpin. Yields after purification.

We also tested challenging unsymmetrical alkynes $\mathbf{3} \mathbf{d}-\mathbf{3} \mathbf{j}$, which can feature problems of regioselectivity, leading to a mixture of $\alpha$ - and $\beta$-vinyl boranes. We were delighted to see that $\mathrm{MgBu}_{2}$ can successfully catalyze the hydroboration of internal aryl-alkyl alkynes $\mathbf{3 d - 3 g}$ leading to $\alpha$-vinyl boranes $\mathbf{4 d - 4 g}$ with regioselectivities from $8: 2$ to $>99: 1 .{ }^{15}$ It is interesting to note that the corresponding aluminum-hydride species were not able to hydroborate this type of unsymmetrical internal alkynes., ${ }^{4,5,16}$ Moreover, and in contrast to sterically hindered alkynes $\mathbf{3 d} \mathbf{d} \mathbf{3 g}$, the predominant regioisomer for the hydroboration of less bulky internal alkyne $\mathbf{3 h}$ is the $\beta$-vinyl borane. Furthermore, by replacing a methyl with an $n$-propyl group (3h vs $\mathbf{3 i}$ ), the regioselectivity is inverted, meaning that the size of the alkyl substituent plays a dominant role in controlling the regioselectivity. 
Table 3. $\mathrm{MgBu}_{2}$-catalyzed hydroboration of internal alkynes. ${ }^{[\mathrm{a}]}$

$$
\mathrm{R} \underset{\mathbf{3 a - 3 j}}{=} \mathrm{R}
$$<smiles>CC1(C)OB(/C(=C/c2ccccc2)c2ccccc2)OC1(C)C</smiles>

4a, $80 \%$

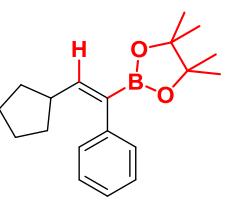

4d, $83 \%^{[c]}, 9: 1$

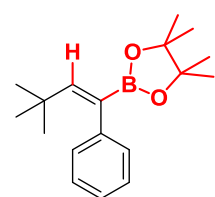

$\mathbf{4 g}, 85 \%[\mathrm{cc},>99: 1$

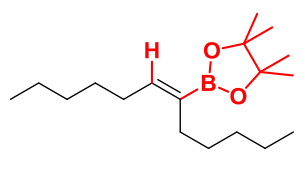

4 b, $80 \%[$ [b]

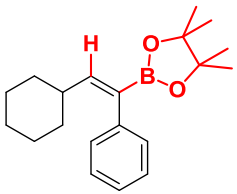

$4 e, 81 \%^{[c]}, 9: 1$

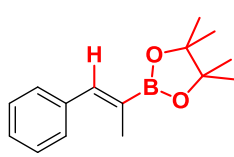

4h, $73 \%, 6: 4$

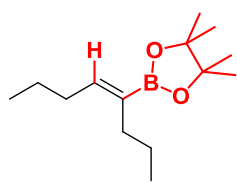

$4 c, 75 \%\left[{ }^{[b]}\right.$

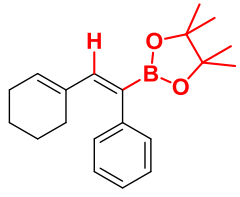

4f, $80 \%[c], 8: 2$<smiles>[R]C(=CCCC)B1OC(C)(C)C(C)(C)O1</smiles>

$4 i, \mathrm{R}=\mathrm{Ph}: 78 \%, 6: 4$ $4 \mathrm{j}, \mathrm{R}=\mathrm{Me}: 70 \%, 7: 3$ of the second HBpin molecule of $\mathbf{A}_{3}$ by a $\mathbf{1 a}$ molecule triggers deprotonation of $\mathbf{1 a}$ via transition state $\left[\mathbf{A}_{4}-\mathbf{A}_{5}\right]^{\ddagger}$, leading to intermediate $\mathbf{A}_{5}$ with a moderate free energy barrier of 25.0 $\mathrm{kcal} / \mathrm{mol}$ from $\mathbf{A}_{3}$. The product is liberated from $\mathbf{A}_{5}$ to regenerate the active species $\mathbf{A}$. Roesky ${ }^{4}$ proposed a similar mechanism for the aluminum catalyzed hydroboration of terminal alkynes.

Within mechanism $B$ the reaction starts with hydrometalation of 1a by the active species $\mathbf{B}$, which leads to the Mg-vinyl intermediate $\mathbf{B}_{1}, 24.2 \mathrm{kcal} / \mathrm{mol}$ lower in energy. This step requires a free energy barrier of $20.2 \mathrm{kcal} / \mathrm{mol}$ to overcome transition state $\left[\mathbf{B}-\mathbf{B}_{1}\right]^{\ddagger}$. The next step consist in nucleophilic migration of the vinyl group to the boron atom of the coordinated $\mathrm{HBpin}$, to give the zwitterionic intermediate $\mathbf{B}_{2}, 4.9 \mathrm{kcal} / \mathrm{mol}$ more stable than $\mathbf{B}_{\mathbf{1}}$. Thereafter, reverse hydride migration from boron to magnesium generates $\mathbf{B}_{\mathbf{3}}$. The significantly lower energy barriers of 8.2 and $5.8 \mathrm{kcal} / \mathrm{mol}$ connected to transition states $\left[\mathbf{B}_{1}-\mathbf{B}_{2}\right]^{\ddagger}$ and $\left[\mathbf{B}_{2}-\mathbf{B}_{3}\right]^{\ddagger}$ suggest that the successive vinyl migration and reverse hydride migration are easy. Finally, the product is liberated from $\mathbf{B}_{\mathbf{3}}$ to regenerate the active catalyst $\mathbf{B}$ for the next catalytic cycle.

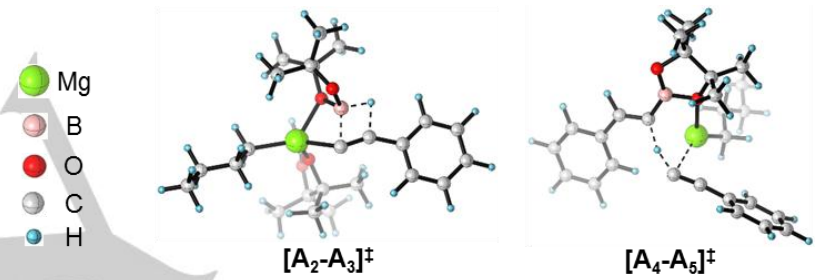

[a] Reaction conditions: $3 a-3 j$ ( 1 mmol), 1.5 equiv. $\mathrm{HBpin}, \mathrm{MgBu}_{2}(10 \mathrm{~mol} \%)$, toluene $(1 \mathrm{~mL}), 80{ }^{\circ} \mathrm{C}$ for $18 \mathrm{~h}$. Regioselectivities determined by ${ }^{1} \mathrm{H}$ NMR spectroscopy; [b] $70{ }^{\circ} \mathrm{C}$; [c] $48 \mathrm{~h}$. Yields after purification.

In order to gain a better understanding of the reaction mechanism we performed DFT calculations at the M06/Def2TZVPP//BP86/Def2-SVP level of theory (for computational details see Supporting Information). Phenylacetylene 1a and diphenylacetylene 3a were used as terminal and internal alkynes, respectively. In case of 1a two alternative pathways were considered (Scheme 2): i) mechanism $A$, starting with reaction of $\mathrm{MgBu}_{2}$ with the terminal $\mathrm{C}-\mathrm{H}$ bond of $\mathbf{1 a}$ to give the active species $\mathbf{A}$, and ii) mechanism $B$, starting with reaction of $\mathrm{MgBu}_{2}$ with HBpin to give the active species $\mathbf{B}$. The energy profiles for formation of the active species $\mathbf{A}$ and $\mathbf{B}$ are displayed in the Supporting Information (Figure S1 and S2). The highest activation barrier for the formation of the active species $\mathbf{A}$ is 25.4 $\mathrm{kcal} / \mathrm{mol}$ (Figure S1), while the highest activation barrier for formation of the active species $\mathbf{B}$ is only $8.9 \mathrm{kcal} / \mathrm{mol}$ (Figure S2). This indicates that formation of $\mathbf{B}$ is remarkably favored over formation of $\mathbf{A}$.

Mechanism A starts with exergonic coordination of two HBpin molecules to $\mathbf{A}$. The resulting intermediate $\mathbf{A}_{\mathbf{2}}$ undergoes hydroboration of the $\mathrm{C} \equiv \mathrm{C}$ bond, with one of the coordinated HBpin molecules, via the $[2 \sigma+2 \pi]$ addition type transition state $\left[\mathbf{A}_{2}-\mathbf{A}_{3}\right]^{\ddagger}$ (Figure 1 for geometry). This step has an activation free energy of $36.5 \mathrm{kcal} / \mathrm{mol}$ (Figure S3), leads to the vinyl intermediate $\mathbf{A}_{3}$, and it is exergonic by $8.6 \mathrm{kcal} / \mathrm{mol}$. Substitution

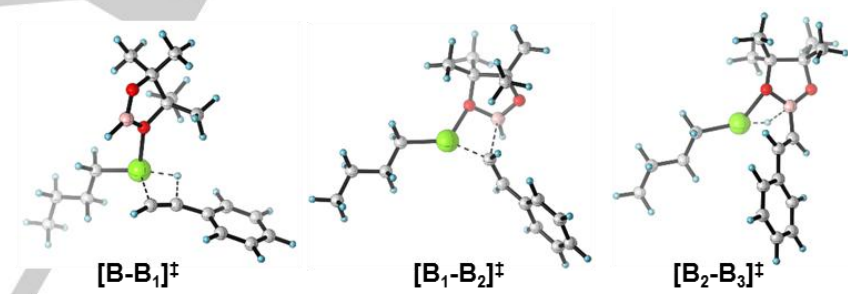

Figure 1. Optimized geometries of transition states involved in mechanism $A$ and mechanism $B$ for 1 a.

Comparison of the energetics of active species formation from $\mathrm{MgBu}_{2}$, and of the reactivity within the catalytic cycles reveals that mechanism $B$ is favored over mechanism $A$, both at the level of active species formation $\left(\Delta \Delta \mathrm{G}^{\ddagger}\right.$ is $\left.16.5 \mathrm{kcal} / \mathrm{mol}\right)$ and within the cycle $\left(\Delta \Delta \mathrm{G}^{\ddagger}\right.$ is $\left.16.3 \mathrm{kcal} / \mathrm{mol}\right)$. Moreover, while mechanism $A$ can only explain the reactivity of terminal alkynes, mechanism $B$ has the advantage of explaining the reactivity of both, terminal and internal alkynes. Finally, to assess the viability of mechanism $B$ for the hydroboration of internal alkynes, we investigated the hydroboration of the internal alkyne $\mathbf{3} \mathbf{a}$, which resulted in a smooth energy profile, similar to that calculated for 1a (Figure S5). 


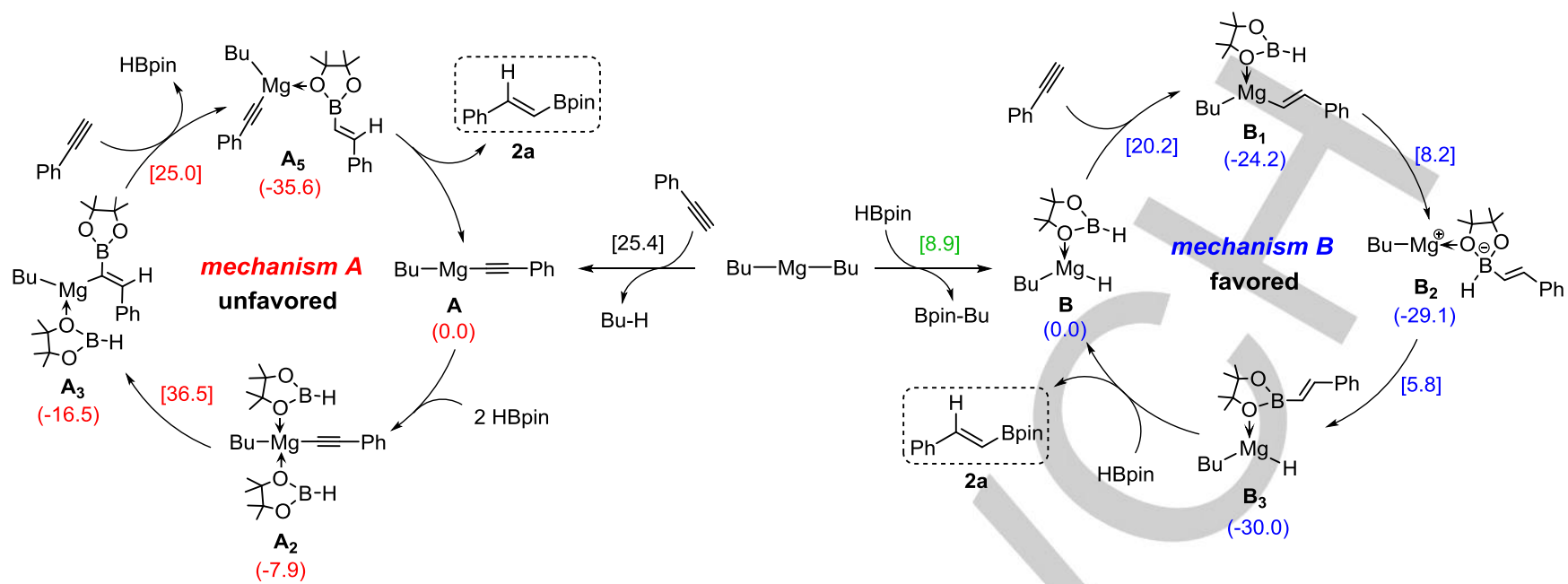

Scheme 2. Proposed mechanism for the $\mathrm{MgBu}_{2}$-catalyzed hydroboration of terminal alkynes. Catalytic cycle for the active catalyst $\mathbf{A}$ represented by $\mathbf{m e c h a n i s m}$ $\boldsymbol{A}$ while catalytic cycle for active catalyst $\mathbf{B}$ is represented as mechanism $\boldsymbol{B}$. In parenthesis the relative free energies (in $\mathrm{kcal} / \mathrm{mol}$ ) of intermediates with respect to active catalysts $\mathbf{A}$ and $\mathbf{B}$ as $0.0 \mathrm{kcal} / \mathrm{mol}$ are presented. In square bracket, the activation free energy barriers for the corresponding steps are given.

To support mechanism $B$, a series of stoichiometric and catalytic experiments were performed (Scheme 3 ). When $\mathrm{MgBu}_{2}$ was mixed with HBpin, the formation of Bpin-Bu was observed, corroborating the presence of the active species $\mathbf{B}$ (Scheme 3a). When equimolar amounts of phenylacetylene 1a were added (Scheme $3 b$ ), quantitative yield of the desired product was detected.

\section{Stoichiometric Experiments}

a) Formation of $\mathrm{BuMgH}$ active species

$$
\begin{array}{ll}
\mathrm{HBpin} & +\mathrm{MgBu}_{2} \underset{\mathrm{d} 8 \text {-toluene }}{23^{\circ} \mathrm{C}} \mathrm{Bu}^{-\mathrm{Mg}_{-}}+\text {Bpin-Bu } \\
5 \text { eq. } & 1 \text { eq. }
\end{array}
$$

b) BuMgH active species: mechanism $B$

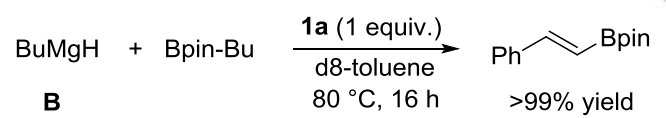

c) Reaction of $\mathrm{MgBu}_{2}$ with 1a

$$
1 \mathrm{a}+\underset{\substack{\mathrm{MgBu} \\ \text { eq. }}}{\stackrel{\mathrm{d} 8 \text {-toluene }}{2}}
$$

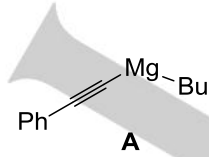

d) Conversion of $\boldsymbol{A}$ to the $\mathrm{BuMgH}$<smiles>Br[13C](Br)c1ccccc1</smiles>

A

$$
\underset{\substack{\text { HBpin (5 equiv.) } \\ 80^{\circ} \mathrm{C}}}{\stackrel{\text { toluene }}{\longrightarrow}}
$$

Scheme 3. Control experiments for mechanistic study.

Furthermore, when a 1:1 mixture of $\mathrm{MgBu}_{2}$ and $1 \mathrm{a}$ was prepared, species A was observed at $23^{\circ} \mathrm{C}$ (Scheme $3 \mathrm{c}$ ), in line with the DFT results (Figure S1). However, treatment of $\mathbf{A}$ with 5 equiv. HBpin provides the BuMgH as indicated by the NMR spectra (Scheme 3d), which is in agreement with the DFT calculations for the interconversion of $\mathbf{A}$ into $\mathbf{B}$ (Figure S6). Therefore, these stoichiometric experiments indicate that $\mathbf{B}$ is the active catalyst and mechanism $B$ is operative instead of mechanism $A$.

In summary, we report an active and selective system for the hydroboration of terminal and internal alkynes and demonstrate that commercially available $\mathrm{MgBu}_{2}$ is an active catalyst for achieving good yields and selectivities under relatively mild reaction conditions and low catalyst loadings (7-10 mol\%). The developed Mg-catalyzed hydroboration of alkynes shows tolerance for functional groups, making this transformation very attractive for late stage functionalization. Moreover, mechanistic studies employing DFT calculations together with experiments show that the hydroboration of alkynes takes place through the hydrometalation of an in situ formed $\mathrm{BuMgH}$ species, followed by $\mathrm{Mg} / \mathrm{B}$ exchange, regenerating the active $\mathrm{BuMgH}$ species and releasing the corresponding vinylborane product. Based on the experimental results and mechanistic insights we anticipate the development of further new magnesium catalyzed $\mathrm{C}-\mathrm{H}-$ functionalizations.

\section{Acknowledgements}

B.M. and L.C. acknowledge King Abdullah University of Science and Technology (KAUST) for computational resources of the supercomputer Shaheen II.

Keywords: hydroboration • alkynes • magnesium • alkalineearth metal $\cdot$ vinyl borane $\cdot$ DFT

[1] a) N. Miyaura, A. Suzuki, Chem. Rev. 1995, 95, 2457; b) S. Kotha, K. Lahiri, D. Kashinath, Tetrahedron 2002, 58, 9633; c) A. Suzuki, Angew. Chem. Int. Ed. 2011, 50, 6722; d) S. Roscales, A. Csáky, Chem. Soc. Rev. 2014, 43, 8215; e) D. Leonori, V. K. Aggarwal, Angew. Chem. Int. Ed. 2015, 54, 1082.

[2] For representative examples using Rh-catalysis, see: a) S. Pereira, M Srebnik, Tetrahedron Lett. 1996, 37, 3283; b) T. Ohmura, Y. Yamamoto, N. Miyaura, J. Am. Chem. Soc. 2000, 122, 4990; c) L. Carreras, M. Serrano-Torné, P. W. N. M. van Leeuwen, A. Vidal-Ferran, Chem. Sci. 
2018, 9, 3644. For Ru-catalysis, see: d) K. Burgess, M. Jaspars, Organometallics 1993, 12, 4197; e) C. Gunanathan, M. Hölscher, F. Pan, W. Leitner, J. Am. Chem. Soc. 2012, 134, 14349; f) B. Sundararaju, A. Fürstner, Angew. Chem. Int. Ed. 2013, 52, 14050. For Ir-catalysis, see: g) J. R. Knorr, J. S. Merola, Organometallics 1990, 9, 3008; h) N. Iwadate, M. Suginome, Org. Lett. 2009, 11, 1899. For Pdcatalysis, see: i) Y. Matsumoto, M. Naito, T. Hayashi, Organometallics 1992, 11, 2732.

[3] For representative examples using Co-catalysis, see: a) J. V. Obligacion, J. M. Neely, A. N. Yazdani, I. Pappas, P. J. Chirik, J. Am. Chem. Soc. 2015, 137, 5855; b) J. Guo, B. Cheng, X. Shen, Z. Lu, J Am. Chem. Soc. 2017, 139, 15316; c) H. Ben-Daat, C. L. Rock, M. Flores, T. L. Groy, A. C. Bowman, R. J. Trovitch, Chem. Commun 2017, 53, 7333. For Fe-catalysis, see: d) M. Espinal-Viguri, C. R. Woof R. L. Webster, Chem. Eur. J. 2016, 22, 11605; e) K. Nakajima, T. Kato, Y. Nishibayashi, Org. Lett. 2017, 19, 4323; f) N. Gorgas, L. G. Alves, B, Stöger, A. M. Martins, L. F. Veiros, K. Kirchner, J. Am. Chem. Soc. 2017, 139, 8130; g) N. Gorgas, B. Stöger, L. F. Veiros, K. Kirchner, ACS Catal. 2018, 8, 7973. For Cu-catalysis, see: h) K. Semba, T. Fujihara, J. Terao, Y. Tsuji, Chem. Eur. J. 2012, 18, 4179; i) Y. D. Bidal, F. Lazreg, C. S. J. Cazin, ACS Catal. 2014, 4, 1564.

[4] Z. Yang, M. Zhong, X. Ma, K. Nijesh, S. De, P. Parameswaran, H. W. Roesky, J. Am. Chem. Soc. 2016, 138, 2548.

[5] A. Bismuto, S. P. Tomas, M. J. Cowley, Angew. Chem. Int. Ed. 2016, 55, 15356.

[6] Further approaches for the hydroboration of alkynes have been published, however, directing groups and aromatic rings in the substrates were necessary to achieve good yields and selectivities: a) H. E. Ho, N. Asao, Y. Yamamoto, T. Jin, Org. Lett. 2014, 16, 4670; b) Y. Wu, C. Shan, J. Ying, J. Su, J. Zhu, L. L. Liu, Y. Zhao, Green Chem. 2017, 19, 4169; c) K. Nagao, A. Yamazaki, H. Ohmiya, M. Sawamura, Org. Lett. 2018, 20, 1861

[7] For recent reviews on the use of organomagnesium complexes (and the corresponding hydride complexes) as catalysts: a) M. R. Crimmin, M. S. Hill, Top. Organomet. Chem. 2013, 45, 191; b) K. Revunova, G. I. Nikonov, Dalton Trans. 2015, 44, 840; c) R. Rochat, M. J. Lopez, H. Tsurugi, K. Mashima, ChemCatChem 2016, 8, 10; d) M. S. Hill, D. J. Liptrot, C. Weetman, Chem. Soc. Rev. 2016, 45, 972; e) H. Pellissier. Org. Biomol. Chem. 2017, 15, 4750.

[8] For selected examples, see: a) M. Arrowsmith, T. J. Hadlington, M. S. Hill, G. Kociok-Kohn, Chem. Commun. 2012, 48, 4567; b) M. Arrowsmith, M. S. Hill, G. Kociok-Köhn, Chem. Eur. J. 2013, 19, 2776; c) D. Mukherjee, A. Ellern, A. D. Sadow, Chem. Sci. 2014, 5, 959; d) L. Fohlmeister, A. Stasch, Chem. Eur. J. 2016, 22, 10235; e) D. Mukherjee, S. Shirase, T. P. Spaniol, K. Mashima, J. Okuda, Chem. Commun. 2016, 52, 13155; f) K. Manna, P. Ji, F. X. Greene, W. Lin, J. Am. Chem. Soc. 2016, 138, 7488.

[9] S. J. Bonyhady, C. Jones, S. Nembenna, A. Stasch, A. J. Edward, G. J. McIntyre, Chem. Eur. J. 2010, 16, 938.

[10] See for instance, a) M. Arrowsmith, B. Maitland, G. Kociok-Köhn, A. Stasch, C. Jones, M. S. Hill, Inorg. Chem. 2014, 53, 10543; b) S. Schnitzler, T. P. Spaniol, L. Maron, J. Okuda, J. Chem. Eur. J. 2015, 21, 11330.

[11] Recently, Parkin and co-workers, reported a Mg- $\mathrm{H}$ complex which is able to hydrosilylate and hydroborate styrene. M. Rauch, S. Ruccolo, G. Parkin, J. Am. Chem. Soc. 2017, 139, 13264. For Magnesium(I) catalysis with a dinuclear magnesium complex, see: J. Li, M. Luo, X. Sheng, H. Hua, W. Yao, S. A. Pullarkat, L. Xu, M. Ma, Org. Chem. Front. 2018, 5, 3538.

[12] Leading examples for the use of $\beta$-diketiminate magnesium complexes in C-H and C-F activations: a) L. Davin, R. McLellan, A. R. Kennedy, E. Hevia, Chem. Commun. 2017, 53, 11650; b) L. Davin, R. McLellan, A. Hernán-Gómez, W. Clegg, A. R. Kennedy, M. Mertens, I. Stepek, E. Hevia, Chem. Commun. 2017, 53, 3653.

[13] For illustrative examples using magnesium organometallics for deprotonation/metalation reactions, see: a) Z. Dong, G. C. Clososki, S.
H. Wunderlich, A. Unsinn, J. Li, P. Knochel, Chem. Eur. J. 2009, 15, 457; b) F. M. Piller, T. Bresser, M. K. R. Fischer, P. Knochel, J. Org Chem. 2010, 75, 4365; c) B. Haag, M. Mosrin, H. lla, V. Malakhov, P. Knochel, Angew. Chem. Int. Ed. 2011, 50, 9794; d) A. D. Benischke, M. Ellwart, M. R. Becker, P. Knochel, Synthesis 2016; 48, 1101.

[14] For the first time, $\mathrm{MgBu}_{2}$ hydroboration of unsaturated bonds is reported without the use of ligand.

[15] Usually alkylphenylacetylenes tend to produce $\beta$-vinylboranes. In our case, bulky alkyl substituted internal alkynes provided selectively the $\alpha$ regioisomer, whereas less bulky alkyl substituents provided the $\beta$ vinylborane as the predominant regioisomer (with reduced regioselectivity).

[16] The aluminum-dihydride species reported by Yang, Parameswaran and Roesky et al. (ref. 4) did not succeed in the hydroboration of internal alkynes. The DIBAL-H / AIEt $t_{3}$. DABCO reported by Thomas and Cowley et al. (ref. 5) were applicable to symmetrical and unsymmetrical alkylalkyl internal alkynes, but not to aryl-alkyl internal alkynes. 


\section{COMMUNICATION}

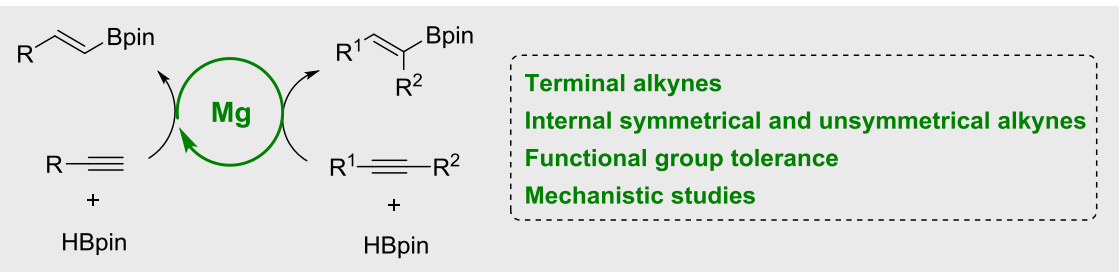

$\mathrm{MgBu}_{2}$ proved to be an efficient catalyst for the hydroboration of terminal and internal alkynes, achieving good yields and selectivities, competing with the best reports in the literature. The compatibility with many functional groups makes the Mg-catalyzed hydroboration of alkynes very attractive as a late stage functionalization protocol. Moreover, experimental investigations together with DFT calculations provide insight into the reaction mechanism.
Marc Magre, Bholanath Maity, Alban Falconnet, Luigi Cavallo* and Magnus Rueping*

Page No. - Page No.

Magnesium-catalyzed hydroboration of terminal and internal alkynes 